\title{
A Study of Clothing Industry Innovation and Development from the Perspective of Ecological Design
}

\author{
Jun YIN \\ Wuhan Textile University, Wuhan, 430073, China \\ email: 12408113@qq.com
}

Keywords: Ecological design; clothing industry; innovation; development

\begin{abstract}
Ecological clothing design has become the main topic of clothing design industry. With ecological design concept penetrating to all the aspects of society life, the clothing industry is also developing ecological clothing under the influence of this concept. Through the interpretation of ecological design concept, it is pointed out that the fashion clothing under the guidance of ecological design concept not only plays a crucial role in the use of ecological textile materials, green ecological clothing design, green marketing strategy, but also has positive and practical influence on promoting the harmonious and sustainable development of human and environment.
\end{abstract}

\section{Introduction}

Background of ecological design development: Appearing in the late 1980s, the ecological design trend was a rapidly developing international design trend in recent years. [1] In the long history of human society, all kinds of designs have created more comfortable social environment and life style. [2] On the other hand, they also accelerate the loss of energy and resources, greatly damaging the human survival environment, the earth. Under this background, the designers have to reconsider their responsibility and role and thus the ecological design concept arise. [3] Ecological design is also called Green Design, Design for Environment, Environmentally Benign Design. Regarding ecological design, it is widely admitted domestically that ecology is the study of the mutual relation between living things and man and the environment and it is the subject studying the structure and function of ecology system and human ecosystem. [4]The ecological design takes the ecological design concept as its guidance and stresses the understanding of environmental concept, limited earth resources, and also the mutually dependent relations among ecosystems and it constructs the overall and systematic design concept on the basis of ecology concept. The ecological design must practice economy and harmlessness from the selection of materials to designing and use the natural resources as little as possible and reduce adverse impact on environment. [5]Moreover, the products should be recycled to achieve no waste and positive cycle. In the guidance of ecological concept, the green ecological civilization is introduced to the industrial field and under this background, the development trend and tide is sure to be ecological design.

\section{The Performance Characteristics of Ecological Design}

Ecological design requires that product development should first balance the ecology and economy need, namely considering the environmental value as well as cost, performance, technology and other commercial values. Next, while meeting economy need, the product must evaluate the influence of entire product life cycle on the environment as well as human health and reduce the negative impact to the largest degree. Currently, the essential feature of ecological design mainly displays in product improvement and product innovation, as is shown in Fig. 1: 


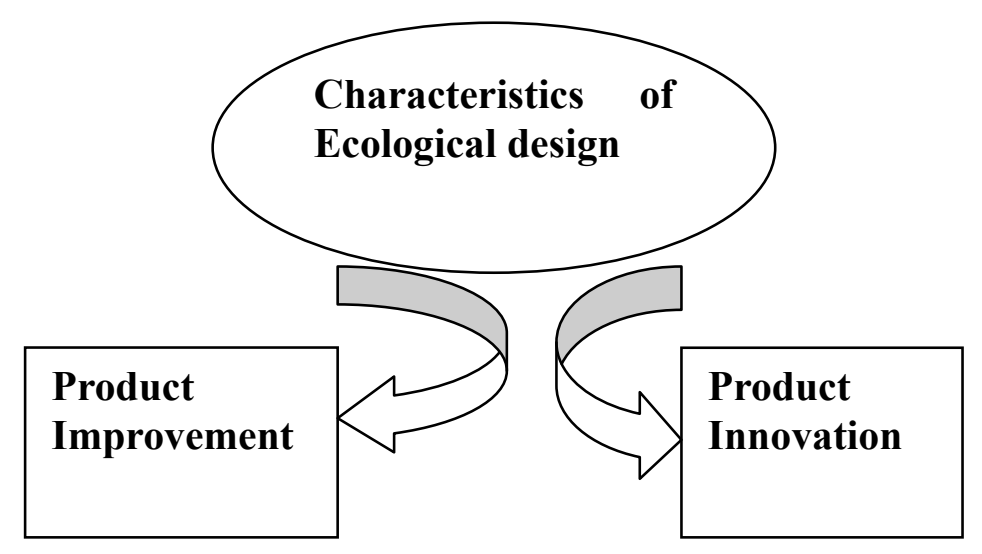

Fig 1 Characteristics of Eeo-Design

Meliorative design of product, also called design for preventing pollution, refers to the adjustment and improvement of the existing product design plan under invariable production technology and product in view of preventing environmental pollution, such as recycling raw clothing material, improving existing clothing processing and performance of auxiliary material and increasing anti-pollution installment in the clothing production.

Innovative design of product, also called "design for preventing pollution", refers to innovative development or alternative process of some components of the product under invariable overall requirement of product design. For example, all-around innovation of product design is conducted in order to change the environmental pollution and resource waste of previous product design, including reducing the type and quantity of raw material and auxiliary material and increasing the use of non-polluting material in terms of clothing material selection; reducing the energy consumption and pollution in clothing production process in terms of production cycle; increasing functional designs and dismountable designs in terms of style design; increasing the possibility of recycle in terms of appearance design. Chinese famous brand down clothing "Bosideng" and "Xuezhongfei" always top the domestic winter clothing market in sales volume and own half of the entire domestic market. The success of the two enterprises cannot be separated from their efforts in ecological design. The two brands both cooperated with US Du Pont Company and used one environment-protecting material as the lining of down clothing. This kind of lining not only keeps out the wind and maintains warmth and has good permeability, but also keeps you sweat-free and wet-free and effectively keeps the lining dry, soft and clean.

\section{The Development of Clothing Industry under the Guidance of Ecological Design Concept}

Ecological design concept displays humans' pursuit of life instinct and abandons blind pursuit of high-tech and stresses the sustainable development of design. Under the guidance of this concept, the fashion industry advances the ecological environment protection and covers the clothing production, consumption and so on.

\section{A. Selecting ecological textile material}

Choosing ecological material is an important part of ecological design. First, environmental and harmless material is needed, which requires that all the fertilizer, fourrage, growth regulator, herbicide and disinfectant should be harmless to human beings in the planting and raising process of plants and animals used for fiber materials. Natural color fiber should be used in the process instead of dyed fiber, e.g., colored cotton. Also, bean, milk, corn, bamboo should be used as new type fiber and they have anti-bacterial and negative oxygen ion function and are ecological material called "second skin". In addition, other ecological materials, such as chitin fiber which is made from shrimp and crab shell, have good anti-bacterial function. Also, wasted chitin fiber product can be broken up quickly in the earth. Solvent used in the Tencel fiber production process is nontoxic and 
$99 \%$ of it can be recycled and also finished goods can be degraded. The Chinese ramie fiber developed by Yageer hasunique anti-bacterial function. With no fertilizer in its planting process and no chemical finishing in its producing process, it saves energy, reduces omission discharge and does not pollute the environment. The ecological choice of material is also shown in the non-poisoning and organizing treatment of materials production process. The research gains natural dyestuff, natural pulp and natural finishing agent from the nature instead of using the existing chemicals. It uses little-water or no-water dyeing and finishing technology and this not only reduces the pollution of textile and garment manufacturing industry to the environment, but also obtains high-quality clothing material that are good for human beings.

\section{B. Adopting the green ecological clothing design strategy}

The fashion brand can aim at its serial products and carries out the green ecological product design extensively and thoroughly and make characteristic analysis of the clothing products in their full cycle according to various stipulations of the ecological textile. Using environmental clothing material and developing versatility of single clothing design and improving the comfortableness of clothing will be key problems that the ecological design concepts need to solve. Traditional textile clothing production causes much pollution to environment, especially the after-treatment stage of the clothing production which requires garment dyeing and garment wash causes varying degrees of pollution to water resources and land resource. But the production planning of fashion brand under the guidance of ecological concept must strictly control the generation of harmful substance in the clothing manufacturing process and final product packing process. Development should apply environmental procedure instead of pollutive water scrubbing and dyeing and it should be accompanied by after-treatment of clothing. Also, the air condition in the manufacturing shop should be improved and production safety and physical and moral integrity of staff need to be guaranteed. The ecological design of clothing should cover the following aspects.

a. Pollution-free production process: no pollution is caused from dress designing, the lining choice, clothes making, packing, and transportation to selling.

b. No harm to human body: dressing, washing and undressing process causes harm to human body and the harmful substance cannot be higher than the related standard of national and international regulation.

c. Pollution-free in the discarded process: clothes can be recycled and degraded, but there should be no harmful substance and air pollution in this process.

d. No waste in energy consumption: renewable material is used as raw material and resources consumption is reduced; also, advanced processing equipment and craft is used and thus energy consumption is decreased.

\section{Green marketing strategy under ecological design concept}

The green marketing channel is the channel through which green product shifts from the producer to the consumer. Short channel and wide channel should be established and channel consumption of resources and channel expense should be reduced. In the managing process of fashion brand, we should always hold green idea and environmental marketing idea, integrate the green environmental idea into the product and advertising, clearly express the ecological theme to the audience and make sure the fashion brand and ecological design coexist and develop harmoniously. Publicity is about how the enterprise transmits its brand information to the target audience. It includes advertisement, public promotion, extraordinary event and network promotion, as is shown in Fig. 2. The strategy of enterprise should concentrate on making people purchase its product, so it should correctly choose the activity. In case of retail, it must understand its target goal. In case of wholesale, it should not only aim at the final customer but also consider the retailer.

\section{Figure--Marketing Functions}

The publicity and promotion of ecological brand is one of most important contents of the clothing industrial innovation and development. Meanwhile, the ecological design concept itself is also one of the influential publicity themes. The paper introduces the representative theory of the marketing strategy, namely the USP theory, to conduct the analysis. USP (Unique selling Proposition) represents unique sales proposition or unique selling point. USP theory 
is first proposed in the 1950s by Rosser Reeves who was president of US Bates Advertisement Company and it was the earliest and far-reaching advertising creative theory. The aim of USP theory is to focus on products. We either look for difference of the product or make adjustments to create product difference or show other aspect of the product if there is no difference.

The publicity image design of ecological fashion brand can focus on the requirement of ecological design and highlight the green, environmental, natural, harmonious, brief and energy-saving principle. The design characteristic and principle of clothing should be considered and complete publicity image should be created to make successes in the market. The publicity of fashion brand which integrates ecological concept need to express the advancement of ecological design to the consumers to make them understand the advantage of buying ecological clothing products. Also, security, healthiness and environmental protection should be stressed to attract the consumers by its uniqueness.

\section{Conclusion}

In recent years, our country has issued many policies to develop ecological economy, showing great determination to improve the environment and adhere to sustainable development. At present, fashion industry is at the promotion stage of transforming from consumption type to environmental and practical type, especially, quite a few enterprises have started more concrete research work, such as innovating product and adjusting marketing structure and have integrated ecological concept into the entire enterprise culture to make it part of enterprise activity. Although developing ecological clothing industry still has long way to go, clothing industry should bear this responsibility in the future development and concretely analyzes the uniqueness of ecological design and take it as its guidance based on the specific circumstances of different regions and different enterprises. Also, it should speed up the construction of ecological industry structure, positively improve the ecological technology craft and innovate ecological clothing to greatly forward the innovation pattern of clothing industry so as to make some contribution to improving the environment and advancing sustainable development.

\section{References}

[1] Alastair Fuad 一Luke .eco Design [M].San Francisco: Chronicle Books LLC, 2002.

[2] .Peter, J. P.\&James, H. D. Marketing Management. 7th ed. [M]. Beijing: Tsinghua University Press, 2004

[3]Peter, D. Marketing Management and Strategy 3rd ed. [M]. Beijing: Post \&Telecom Press.2006

[4] 49.Zeshu Takamura. Fashion Design Techniques[M]. Keng Song, 2007.

[5] John W. Schouten, James H. McAlexander, Harold F. Koenig. Transcendent customer experience and brand community [J]. Academy of Marketing Science, 2007:357-368 